\title{
Anti-inflammatory and antioxidant properties of Eriobotrya japonica leaves extracts
}

\author{
Kammoun Maher ${ }^{1,2}$, Ben Ali Yassine ${ }^{1}$, Bezzine Sofiane ${ }^{1}$
}

1. Laboratoire de Biochimie et de Génie Enzymatique des Lipases, Ecole Nationale d'Ingénieurs de Sfax BP11733038, University of Sfax, Tunisia.

2. Laboratoire de Génie Enzymatique et de Microbiologie, Ecole Nationale d’Ingénieurs de Sfax BP1173-3038, University of Sfax, Tunisia.

\begin{abstract}
Background: In the present work we determined phenolic and flavonoids content of Eriobotrya japonica leaves extracts and fractions and their antioxidant and anti-inflammatory properties.

Objectives: To evaluate the inhibition of inflammatory PLA2 and antioxidant effects of extracts and fractions from Eriobotrya japonica leaves

Methods: Antioxidant activity was evaluated with DPPH radical scavenging assay and anti-inflammatory effect of fractions was measured by their inhibition potency on the human pro-inflammatory phospholipase A2 (group IIA).

Results: The EtOH/EtOAc 2:1 extract exhibited a potent inhibition of the hG-IIA with an IC50 values of $8 \mu \mathrm{g} / \mathrm{ml}$. It also shows an antioxidant activity measured on DPPH with an IC50 of $42 \mu \mathrm{g} / \mathrm{ml}$. Fractionation shows that CH2Cl2/MeOH 0:1 fraction was the rich one on flavonoids compounds $(4.3 \mathrm{mg} / \mathrm{g}$ dry weight) and demonstrates a high antioxidant activity with an IC50 of $12 \mu \mathrm{g} / \mathrm{ml}$. The anti-inflammatory evaluation demonstrates that the same fraction was the best one to inhibit the pro-inflammatory phospholipase A2 group IIA with an IC50 of $4 \mu \mathrm{g} / \mathrm{ml}$.

Conclusion: Study conducted on Eriobotrya japonica shows that $\mathrm{CH} 2 \mathrm{Cl} 2 / \mathrm{MeOH}$ 0:1 fraction inhibits efficiently the hGIIA phospholipase.which is considered as pro-inflammatory enzyme.
\end{abstract}

Keywords: Eriobotrya japonica, extraction, flavonoids, anti-inflammatory.

DOI: http://dx.doi.org/10.4314/ahs.v15i2.39

\section{Introduction}

Eriobotrya japonica Lindl, also known as 'loquat', belongs to the Rosaceae family. This plant is an evergreen shrub or small tree with narrow leaves that are dark green on the upper surface and have a lighter color under surface. It is originated from south-eastern China and later became naturalized in Korea, Japan, India and many other countries.

Leaves of Eriobotrya japonica (LEJ) Lindl (Rosaceae) have been used as traditional medicines for lung and stomach diseases and have been found to be effective in chronic bronchitis, inflammation, asthma, low back pain and tumor. ${ }^{1-3,4}$ Studies have demonstrated that
Corresponding author:
Bezzine Sofiane
Laboratoire de Biochimie et
de Génie Enzymatique des Lipases,
Ecole Nationale d'Ingénieurs de Sfax
BP1173-3038, University of Sfax, Tunisia
E-mail : sofiane_bezzine@yahoo.com

LEJ has anti-inflammatory activity in a 12-O-tetradecanoylphorbol-13-acetate induced inflammation model. These reports strongly suggest that LEJ can be used as an anti-inflammatory agent.

Various triterpenes, sesquiterpenes, flavonoids, tannins and megastigmane glycosides have been found in the LEJ and previous studies showed that some of these components have anti-tumor, antiviral, hypoglycemic, antioxidant and anti-inflammatory properties ${ }^{3,5-8}$.

During the inflammatory process, macrophages produce nitric oxide, cytokine and pro-inflammatory enzymes such as secreted phospholipase A2 (sPLA2) ${ }^{9,10}$ that catalyze the hydrolysis of membrane phospholipids to produce free arachidonic acid and lysophospholipids. Indeed, several studies showed that sPLA2 are the chief actors on the biosynthesis of lipid mediators in inflammatory cells ${ }^{11}$. sPLA2 enzymes are a heterogenic family that are divided on 11 groups (IB, IIA, IIC, IID, IIE, IIF, III, V, X, XIIA and XIIB) $)^{12-14}$. The sPLA2 group IIA was initially detected in synovial fluid of patients with rheumatoid arthritis ${ }^{15,16}$. Several studies demonstrated that the sPLA2 group IIA was involved 
A2 ind many phospholipases A2 inhibitors have been discovered and their effectiveness have been proved as a treatment of inflammatory diseases $^{20-22}$.

Because overproduction of these inflammatory mediators might cause inflammatory damage, we focused in the present study on the evaluation of the anti-inflammatory effect of LEJ extracts by measuring the inhibition of the pro-inflammatory sPLA2 group IIA as well as their antioxidant activity.

\section{Material and methods}

\section{Plant material}

Leaves of Eriobotrya Japonica (Rosaceae) (LEJ) were collected in the region from Sfax (Tunisia) in June 2010 The plant was identified by Pr. M. Chaieb (Faculty of Sciences, Sfax University, Tunisia) and a voucher specimen has been deposited in the Chemical Laboratory of Narural Products (Sfax, Tunisia: No. LCSN 108)

\section{Extraction and fractionation of flavonoids}

The dry leaves of plant sample were ground to fine powder in a mill, and $100 \mathrm{~g}$ of powder was extracted in $1 \mathrm{~L}$ of $\mathrm{MeOH} / \mathrm{H} 2 \mathrm{O}$ 7:3. After filtration, the methanol was removed by evaporation and $250 \mathrm{~mL}$ of $\mathrm{n}$-butanol was added. The organic phase was evaporated and the extract was dissolved in $200 \mathrm{~mL}$ of EtOH/EtOAc 2:1. The issue sample was separated on four fractions using $\mathrm{CH} 2 \mathrm{Cl} 2 / \mathrm{MeOH}$ at 8:2, 7:3, 5:5 and 0:1 proportion, respectively.

\section{Total phenols determination} dhe fractions of Erio- by the inhibition of the human inflammatory phosphobotrya japonica leaves extracts was determined by col- lipase A2 group IIA (hG-IIA). The hG-IIA activity was orimetric assay according to the method described by measured as described by ${ }^{28}$. Briefly, the substrate con${ }^{23} .1 \mathrm{ml}$ of sample at $1 \mathrm{mg} / \mathrm{ml}$ was mixed with $1 \mathrm{ml}$ of sisted of $3.5 \mathrm{mM}$ lecithin (Sigma Aldrich) in a mixture Folin-Ciocalteu reagent. After 3 min of incubation, 1 of $3 \mathrm{mM} \mathrm{NaTDC}, 100 \mathrm{mM} \mathrm{NaCl}, 10 \mathrm{mM} \mathrm{CaCl} 2$ and $\mathrm{ml}$ of saturated $\mathrm{Na}_{2} \mathrm{CO}_{3}$ solution was added and the $0.055 \mathrm{mM}$ red phenol as colorimetric indicator in 100 volume was adjusted to $10 \mathrm{ml}$ with distilled water. The $\mathrm{mL} \mathrm{H} 2 \mathrm{O}$. The $\mathrm{pH}$ of the reaction mixture was adjusted reaction mixture was kept in the dark for $90 \mathrm{~min}$, after to 7.6. The hG-IIA or the pig pancreatic phospholipase which the absorbance was read at $725 \mathrm{~nm}$. The total A2 group IB (pG-IB) phospholipases were solubilized phenolic content was determined using gallic acid as a in $10 \%$ acetonitrile at a concentration of 0.02 and 0.002 standard.

\section{Determination of flavonoids conten}

Total flavonoids were determined by following the procedure $^{24}$. Briefly, $1 \mathrm{~mL}$ of aliquots of leaves extracts and fractions were placed in two test tubes, respectively. 7 $\mathrm{mL}$ of methanol were added to one tube. In the other one, $1 \mathrm{~mL}$ of $2 \% \mathrm{ZrOCl} 2-8 \mathrm{H} 2 \mathrm{O}$ and $6 \mathrm{~mL}$ of methsolutions was incubated for $20 \mathrm{~min}$ at room temperature with $10 \mu \mathrm{l}$ of each LEJ extracts and fractions. Then, $\mathrm{mL}$ of the PLA2 substrate was injected in the medium, and the kinetic of hydrolysis was followed during $5 \mathrm{~min}$ ition percentage was calculated by comparison wit experiment and the 1 C50 values were deter-

$10 \mu$ of the enzyme (hG-IIA or pG-IB) and $10 \mu \mathrm{l}$ of Results the corresponding organic solvent.

\section{Statistical analysis stud}

Experimental results were given as mean value \pm SD of three separate experiments. Statistical analysis was conducted using Microsoft Excel software using the Duncan test performed after analysis of variance (ANOVA).

\section{Table 1. Extraction yields of LEJ}

\begin{tabular}{|c|c|}
\hline Solvents & Yields ( $\mathrm{g} / 100 \mathrm{~g}$ dry weight) \\
\hline Methanol/water (70/30) & 15 \\
\hline Butanol & 12 \\
\hline Ethanol-Ethyl acetate $(2 / 1)$ & 9 \\
\hline $\mathrm{CH}_{2} \mathrm{Cl}_{2}-\mathrm{MeOH}(8 / 2)$ & 1.2 \\
\hline $\mathrm{CH}_{2} \mathrm{Cl}_{2}-\mathrm{MeOH}(7 / 3)$ & 2.4 \\
\hline $\mathrm{CH}_{2} \mathrm{Cl}_{2}-\mathrm{MeOH}(5 / 5)$ & 3.1 \\
\hline Methanol & 2.3 \\
\hline
\end{tabular}

Total phenolic and flavonoids content Total phenolic content, expressed as mg GAEs/g DW and flavonoids content, expr DW of LEJ extacts wee presented in 1 show that phenolic and flavonoids content in $\mathrm{EtOH} /$ EtOAc 2:1 extract were about $28 \mathrm{mg}$ GAEs/g DW and $7 \mathrm{mg}$ EQ/g DW, respectively. These concentrations were lower than those from E. japonica cv. Zaozhong

No. 6 and E. japonica Lind ${ }^{29}$. These studies show that

Table 2. Phenolic and Flavonoids content in each fraction and their antioxidant activity. Component (mg/g dry weight)

\begin{tabular}{cccc}
\hline Fractions & Phenolic & Flavonoids & $\begin{array}{c}\text { IC } \\
\text { radical } \mathbf{~ o p} \mathbf{\mu g} / \mathbf{m L})\end{array}$ \\
\hline Ethanol-ethyl acetate $(2 / 1)$ & $28 \pm 1.3$ & $7 \pm 0.52$ & $42 \pm 2.1$ \\
\hline $\mathrm{CH}_{2} \mathrm{Cl}_{2}-\mathrm{MeOH}(8 / 2)$ & $2 \pm 0.04$ & $0.4 \pm 0.03$ & $83 \pm 3.0$ \\
\hline $\mathrm{CH}_{2} \mathrm{Cl}_{2}-\mathrm{MeOH}(7 / 3)$ & $5 \pm 0.07$ & $0.8 \pm 0.03$ & $67 \pm 2.4$ \\
\hline $\mathrm{CH}_{2} \mathrm{Cl}_{2}-\mathrm{MeOH}(5 / 5)$ & $8 \pm 0.09$ & $1.4 \pm 0.08$ & $35 \pm 1.7$ \\
\hline $\mathrm{CH}_{2} \mathrm{Cl}_{2}-\mathrm{MeOH}(0 / 1)$ & $13 \pm 0.4$ & $4.3 \pm 0.1$ & $12 \pm 0.8$ \\
\hline $\mathrm{BHT}$ & - & - & $69 \pm 3.2$ \\
\hline & & &
\end{tabular}

\section{DPPH radical scavenging activity}

The antiradical activities of the extracts were determined using the DPPH free radical assay (figure 2) and the radical scavenging activities were expressed as the mean of the IC50 values $(\mu \mathrm{g} / \mathrm{mL})$. IC50 values and $\mathrm{BHT}$ were reported in Table 2. Our results show that the EtOH/EtOAc 2:1 extracts exhibit a capacity to reduce the DPPH with an IC50 of $42 \mu \mathrm{g} / \mathrm{mL}$. Us- the two species contain 47.5 and $54.9 \mathrm{mg}$ GAEs/g DW as phenolic content and 109.3 and $119 \mathrm{mg}$ QE/g DW/ as ponoids content, respectively. Therefore, the EtOH/

OAc 2:1 extract of LEJ was further fractionated into (8:2, 7:3, 5:5 and 0:1) soluble fractions. Results reported in Table 2 show that $\mathrm{CH} 2 \mathrm{Cl} 2 / \mathrm{MeOH}$ (0:1) extract was the richest on phenolic and flavonoids compound with $13 \mathrm{mg}$ GAEs/g DW and $4.3 \mathrm{mg}$ QE/g by reading the decrease of $\mathrm{OD}$ at $558 \mathrm{~nm}$. The inh ing this extract, the most potent fraction obtained with $\mathrm{CH} 2 \mathrm{Cl} / \mathrm{MeOH} 0: 1$ shows an IC50 value about $12 \mu \mathrm{g} /$ $\mathrm{mL}$, being 3.5 times more active than the initial extract. This result shows that there is correlation between the enrichment of phenolic and flavonoids compounds and the antiradical activity. Consequently, we can hypothesize that phenolic or flavonoids compounds might be responsible for the antiradical activity. 
Figure 2: Radical scavenging activities of LEJ extracts and fractions measured on DPPH.

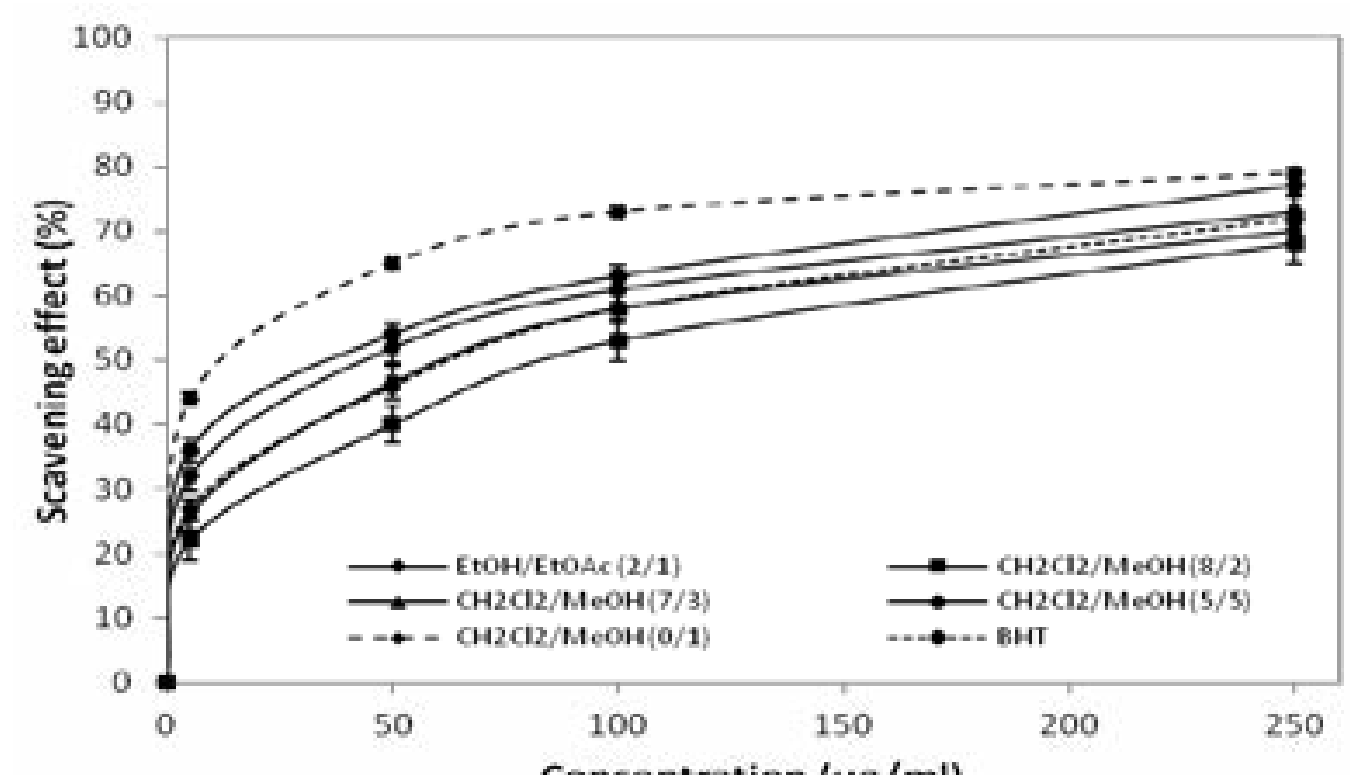

Evaluation of the anti-inflammatory effect

the ability of these extracts and fractions to inhibit the To evaluate the anti-inflammatory effect, we measured inflammatory hG-IIA (figure 3A, 3B) and the digestive pG-IB (figure 3C) phospholipases A2. Figure 3: Inhibitory effect of LEJ extracts and fractions on PLA2. A and B: pro-
inflammatory PLA2 (hG-IIA), C: digestive PLA2 (pG-IB).

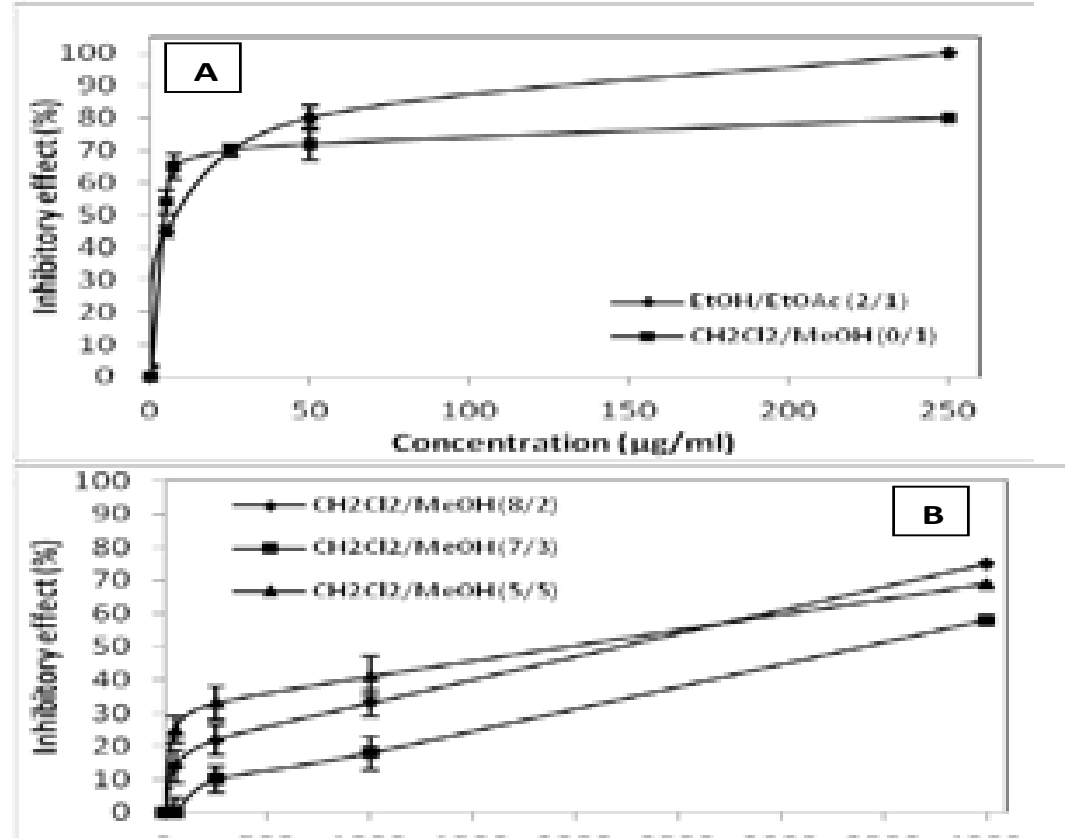

$5001000150020002500 \quad 300035004000$

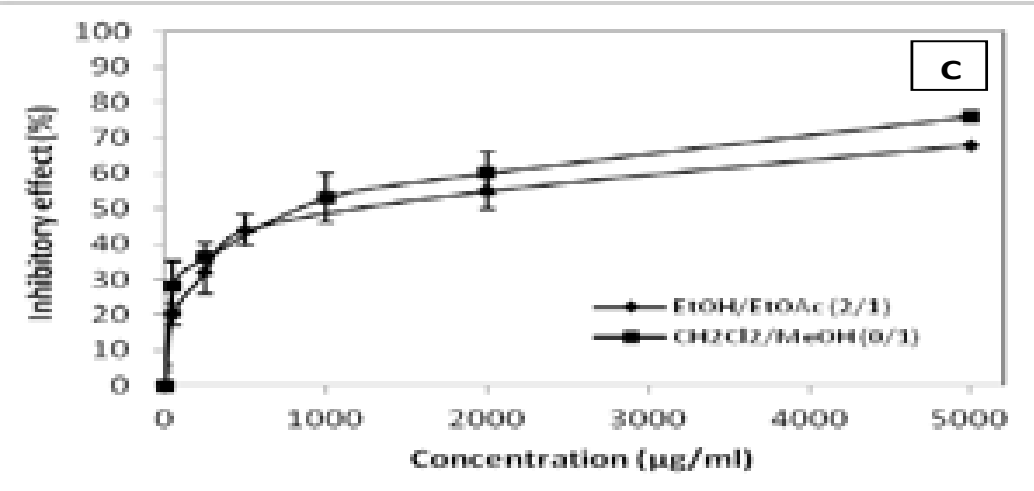

Results show that the EtOH/EtOAc 2:1 extract in- tially hG-IIA with a relative specificity inhibition factor hibits the hG-IIA PLA2 and the pG-IB with an IC50 of about 150. Fractions from this extract were tested of $8 \mu \mathrm{g} / \mathrm{mL}$ and $1200 \mu \mathrm{g} / \mathrm{mL}$, respectively (Table 3). for their ability to inhibit these two PLA2 and results This finding proves that this extract inhibits preferen- revealed that $\mathrm{CH} 2 \mathrm{Cl} 2 / \mathrm{MeOH} \mathrm{0:1} \mathrm{fraction} \mathrm{is} \mathrm{the} \mathrm{most}$ interesting one (Table 3).

Table 3. Inhibitory effect of LEJ extracts on hG-IIA and pG-IB phospholipases.

\begin{tabular}{|c|c|c|c|}
\hline Fractions & $\begin{array}{c}\mathrm{IC}_{50} \text { values on } \\
\text { hG-IIA }(\mu \mathrm{g} / \mathrm{mL})\end{array}$ & $\begin{array}{l}\text { IC }_{50} \text { values on } \\
\text { pG-IB }(\mu \mathrm{g} / \mathrm{mL})\end{array}$ & $\begin{array}{c}\text { Inhibition specificity } \\
\text { (IC } 50 \text { pG-IB /IC } 50 \text { hG-IIA) }\end{array}$ \\
\hline Ethanol-ethyl acetate $(2 / 1)$ & $8 \pm 0.4$ & $1200 \pm 50$ & 150 \\
\hline $\mathrm{CH}_{2} \mathrm{Cl}_{2}-\mathrm{MeOH}(8 / 2)$ & $2300 \pm 100$ & $>5000$ & $>2.17$ \\
\hline $\mathrm{CH}_{2} \mathrm{Cl}_{2}-\mathrm{MeOH}(7 / 3)$ & $3500 \pm 120$ & $>5000$ & $>1.42$ \\
\hline $\mathrm{CH}_{2} \mathrm{Cl}_{2}-\mathrm{MeOH}(5 / 5)$ & $1000 \pm 40$ & $>5000$ & $>5$ \\
\hline $\mathrm{CH}_{2} \mathrm{Cl}_{2}-\mathrm{MeOH}(0 / 1)$ & $4 \pm 0.3$ & $800 \pm 20$ & 200 \\
\hline
\end{tabular}

In fact, this fraction inhibits preferentially the hG-IIA hibitory potency of this fraction toward hG-IIA is enzyme with an $\mathrm{IC}_{50}$ of $4 \mu \mathrm{g} / \mathrm{mL}$ versus $800 \mu \mathrm{g} / \mathrm{mL} 200$ times higher than its toward pG-IB. This fraction measured on pG-IB PLA2. To highlight the specifici- was likely able to inhibit preferentially the inflammatoty inhibition of hG-IIA versus pG-IB, we calculate the ry PLA2 (hG-IIA) and not the digestive one (pG-IB). specificity factor $I C 50(p G-I B)$ Moreover, we can strongly suggest that phenolic or IC50 (hG-IIA) flavonoid compounds in $\mathrm{CH} 2 \mathrm{Cl} / \mathrm{MeOH}$ 0:1 were rewhich is around 200. This value indicates that the in- sponsible for the hG-IIA inhibition.

\section{Figure 1: Standard curve of quercitin}

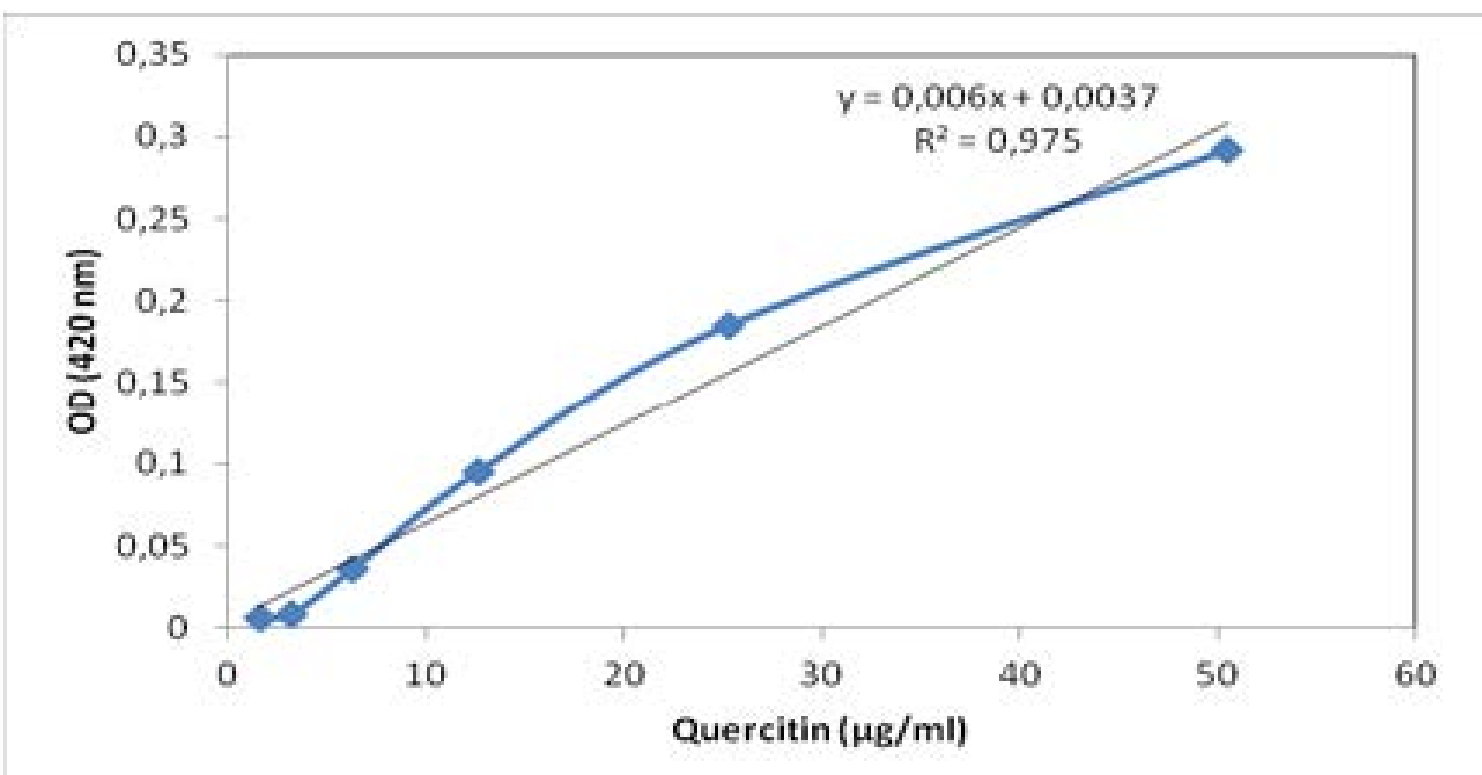

\section{Discussion}

idant ${ }^{24,30-32}$, anti-inflammatory ${ }^{33,34}$, anti-atherosclerotIn this study, we targeted the extraction of phenolic ic $\mathrm{ic}^{35,36}$, anticancer ${ }^{3,3,37,38}$ and antimicrobial activities ${ }^{39,40}$ and flavonoids compounds present in LEJ. In fact, sev- Indeed, the ethanol-ethyl acetate (2/1) extract contains eral previous works described the importance of the $28 \mathrm{mg} \mathrm{GAE} / \mathrm{g} \mathrm{DW}$ of phenolic compounds and $7 \mathrm{mg}$ biological functions of these molecules such as antiox- EQ/g DW of flavonoid contents and show an impor- 
tant antioxidant activity measured on DPPH with an Trachelosermum jasminoide show $\mathrm{IC}_{50}$ values of 112 , IC50 of $42 \mu \mathrm{g} / \mathrm{mL}$. These results are in agreement with 54 and $33 \mu \mathrm{g} / \mathrm{mL}$, respectively ${ }^{43}$. Compared to these those obtained $\mathrm{by}^{41} \mathrm{and}^{24}$ who reported that there is a works, the fractions that we obtained are more efficien close relationship between phenolic and flavonoid con- to inhibit the pro-inflammatory PLA2 with an IC50 of tent and the antioxidant activity in Eriobotrya japonica $4 \mu \mathrm{g} / \mathrm{ml}$.

extracts.

On the purpose to identify natural anti-inflammatory compounds, several studies were performed using Eriobotrya japonica due to its well known potent anti-inflammatory effects ${ }^{42}$ and these have demonstrated that leaf of Eriobotrya japonica was able to suppress LPS-induced cytokine production in a dose dependent manner. Moreover, ${ }^{8}$ they have proved that water extract of Eriobotrya japonica leaves regulates production of pro-inflammatory cytokines such as TNF $\alpha$, IL6 and IL8 in mast cells. We also reported in this study that the ethanol-ethyl acetate (2/1) extract of Eriobotrya japonica inhibits the pro-inflammatory PLA2 (hG-IIA) with an $\mathrm{IC}_{50}$ of $8 \mu \mathrm{g} / \mathrm{mL}$. The selective inhibition was performed using the digestive PLA2 (pG-IB) and our the pancreatic enzyme with an IC of $1200 \mu \mathrm{g} / \mathrm{n}$

This result confirms that the extract inhibits preferentially the pro-inflammatory PLA2 with a relative selectivity factor of 150 . These results have encouraged us to split over this extract. On this purpose, liquid-liquid extraction was performed using $\mathrm{CH}_{2} \mathrm{Cl}_{2} / \mathrm{MeOH}$ at various percentages. Obtained fractions were evaluated for their phenolic and flavonoids content and their ability to possess antioxidant and anti-inflammatory activities. Results presented in Table 2 show that $\mathrm{CH}_{2} \mathrm{Cl}_{2} / \mathrm{MeOH}$ $0: 1$ fraction was the richest on phenolic and flavonoids content with values of $13 \mathrm{mg}$ EAG/g DW and $4.3 \mathrm{mg}$ $\mathrm{EQ} / \mathrm{g} \mathrm{DW}$, respectively, and with the most antioxidan effect $\left(\mathrm{IC}_{50}=12 \mu \mathrm{g} / \mathrm{mL}\right)$. In the same way, this fraction has demonstrated the best capacity to inhibit hG-IIA versus pG-IB with IC50 values of $4 \mu \mathrm{g} / \mathrm{mL}$ and 800 $\mu \mathrm{g} / \mathrm{mL}$, respectively. These results suggest that the phenolic and flavonoids compounds in $\mathrm{CH}_{2} \mathrm{Cl}_{2} / \mathrm{MeOH}$ 0:1 are responsible for preferential inhibition of hG-IIA compared to the digestive pG-IB one.

Several studies investigated medicinal plants for their potent natural therapeutic virtues and only few of them were described for their capacity to inhibit the inflammatory PLA2 enzyme. The ethanol extract of the stem of Sinomenium acutum, Spatholobus suberectus and

\section{Conclusion}

The aim of the present study was to evaluate the anti-inflammatory and the antioxidant activities of phenolic and flavonoids content in Eriobotrya japonica leaves To that end, we performed fractionation of $\mathrm{EtOH} /$ EtOAc 2:1 using $\mathrm{CH}_{2} \mathrm{Cl}_{2} / \mathrm{MeOH}$ in different proportions. The evaluation of these fractions shows that correlation may exist between phenolic and flavonoids compounds and the anti-inflammatory and the antioxidant activities.

So far we are using extract from LEJ and its fraction; the compound responsible for the preferential inhibition of the hG-IIA PLA2 is still not identified. The efforts in purification and identification of active components from LEJ are ongoing.

Abbreviations: $\mathrm{IC}_{50}$ : inhibitory concentration at $50 \%$ sPLA2: secreted phospholipase A2, hG-IIA: human secreted phospholipase A2 group IIA, pG-IB: pig secreted phospholipase A2 group IB, LEJ: leaves of Eriobotrya japonica, DPPH: 2,2-diphényl 1-picrylhydrazyl, $\mathrm{CH}_{2} \mathrm{Cl}_{2}$ : dichloromethane, $\mathrm{MeOH}$ : methanol, DW: dry weight, GAE: gallic acid equivalent, QE: quercitin quivalent, NaTDC: sodium taurodeoxycholate

\section{Acknowledgements}

This research was supported by « Ministère de l'enseignement supérieur et de la recherche scientifique-Tunisia » through a grand to « Laboratoire de Biochimie et de Génie Enzymatique des Lipases-ENIS » (Tunisia)

\section{References}

1. Kimura T, But PPH, Guo J-X, Sung CK, editors. International Collation of Traditional and Folk Medicine: Northeast Asia. World Scientific Pub Co Inc; 1996.

2. Zhu Y-P. Chinese Materia Medica: Chemistry, Pharmacology and Applications. Harwood Acad. Publ.; 1998 Sakagami H, Kusama K, Satoh K, Sugita D, Shimura S, toh Y, Yoshida T. Polyphenols from Eriobotrya japon-
3. Ito H, Kobayashi E, Takamatsu Y, Li SH, Hatano T ica and their cytotoxicity against human oral tumor cell lines. Chem. Pharm. Bull. 2000 May;48:687-693.

4. Banno N, Akihisa T, Tokuda H, Yasukawa K, Taguch

Y, Akazawa H, Ukiya M, Kimura Y, Suzuki T, Nishino H. Anti-inflammatory and antitumor-promoting effects of the triterpene acids from the leaves of Eriobotrya aponica. Biol. Pharm. Bull. 2005 Oct;28:1995-1999.

5. Shimizu M, Fukumura H, Tsuji H, Tanaami S, Hayashi T, Morita N. Anti-inflammatory constituents of topically applied crude drugs. I. Constituents and anti-inflammatory effect of Eriobotrya japonica LINDL. Chem. Pharm. Bull. 1986 Jun;34:2614-2617.

6. De Tommasi N, De Simone F, Cirino G, Cicala C Pizza C. Hypoglycemic effects of sesquiterpene glycosides and polyhydroxylated triterpenoids of Eriobotrya japonica. Planta Med. 1991 Oct;57:414-416.

7. Taniguchi S, Imayoshi Y, Kobayashi E, Takamatsu

Y, Ito H, Hatano T, Sakagami H, Tokuda H, Nishino H, Sugita D, Shimura S, Yoshida T. Production of bioactive triterpenes by Eriobotrya japonica calli. Phytochemistry. 2002 Feb;59:315-323.

8. Kim S-H, Shin T-Y. Anti-inflammatory effect of leaves of Eriobotrya japonica correlating with attenuation of p38 MAPK, ERK, and NF-kappaB activation in mast cells. Toxicol In Vitro. 2009 Oct;23:1215-1219. 9. Tsukahara Y, Morisaki T, Horita Y, Torisu M, Tanaka M. Phospholipase A2 mediates nitric oxide production by alveolar macrophages and acute lung injury in pancreatitis. Ann. Surg. 1999 Mar;229:385-392.

10. Granata F, Frattini A, Loffredo S, Del Prete A, Sozzani S, Marone G, Triggiani M. Signaling events involved in cytokine and chemokine production induced by secretory phospholipase A2 in human lung macrophages. European Journal of Immunology. 2006;36:1938-1950. 11. Kudo I, Murakami M. Phospholipase A2 enzymes. Prostaglandins \& Other Lipid Mediators. 2002 Aug;686rostagla

2. Valentin E, Lambeau G. Increasing molecular diversity of secreted phospholipases A2 and their receptors and binding proteins. Biochimica et Biophysica Acta (BBA)- Molecular and Cell Biology of Lipids. 2000 Oct;1488:59-70

13. Murakami M, Kudo I. Diversity and regulatory functions of mammalian secretory phospholipase A2s. Advances in Immunology [Internet]. Academic Press; 2001 [cited 2013 Feb 13]. p. 163-194. Available from: http://www.sciencedirect.com/science/article/pii/ S0065277601770174.

14. Lambeau G, Gelb MH. Biochemistry and physio- of mammalian secreted phospholipases A2. Annu. Rev. Biochem. 2008;77:495-520.

. The growing phospholipase A2 superfamily of signal transduction enzymes. Trends in Biochemical Sciences. 1997 Jan;22:1-2.

16. Murakami M, Shimbara S, Kambe T, Kuwata H, Winstead MV, Tischfield JA, Kudo I. The functions of five distinct mammalian phospholipase A2S in regulating arachidonic acid release. Type IIa and type V secretory phospholipase $\mathrm{A} 2 \mathrm{~S}$ are functionally redundant and act in concert with cytosolic phospholipase A2. J. Biol. Chem. 1998 Jun;273:14411-14423.

17. Pruzanski W, Albin-Cook K, Laxer RM, MacMillan Stefanski E, Vadas P, Silverman ED. Phospholipase A2 in juvenile rheumatoid arthritis: correlation to disease type and activity. J. Rheumatol. 1994 Oct;21:19511954

8. Kitsiouli E, Nakos G, Lekka ME. Phospholipase A2 subclasses in acute respiratory distress syndrome. Biochim. Biophys. Acta. 2009 Oct;1792:941-953.

19. Granata F, Frattini A, Loffredo S, Staiano RI, Petraroli A, Ribatti D, Oslund R, Gelb MH, Lambeau G, Marone G, Triggiani M. Production of vascular endothelial growth factors from human lung macrophages induced by group IIA and group X secreted phospholipases A2. J. Immunol. 2010 May;184:5232-5241.

20. Snyder DW, Bach NJ, Dillard RD, Draheim SE, Carlson DG, Fox N, Roehm NW, Armstrong CT, Chang CH, Hartley LW, Johnson LM, Roman CR, Smith AC, Song M, Fleisch JH. Pharmacology of LY315920/S-5920, [[3-(aminooxoacetyl)-2-ethyl-1- (phenylmethyl)-1H-indol-4-yl]oxy] acetate, a potent and selective secretory phospholipase A2 inhibitor: A new class of anti-inflammatory drugs, SPI. J. Pharmacol. Exp. Ther. 1999 Mar;288:1117-1124.

21. Reid RC. Inhibitors of secretory phospholipase A2 group IIA. Curr. Med. Chem. 2005;12:3011-3026.

22. Rosenson RS. Future role for selective phospholipase A2 inhibitors in the prevention of atherosclerotic cardiovascular disease. Cardiovasc Drugs Ther. 2009 Feb;23:93-101.

23. Singleton VL, Rossi JA. Colorimetry of Total Phenolics with Phosphomolybdic-Phosphotungstic Acic Reagents. Am. J. Enol. Vitic. 1965 Jan;16:144-158.

24. Zhou C, Sun C, Chen K, Li X. Flavonoids, Phenolics, and Antioxidant Capacity in the Flower of Eriobotrya japonica Lindl. Int J Mol Sci. 2011;12:2935-2945. 25. Brand-Williams W, Cuvelier ME, Berset C. Use of a free radical method to evaluate antioxidant activity. LWT - Food Science and Technology. 1995;28:25-30. 
26. Chen Y, Wang M, Rosen RT, Ho CT. 2,2-Diphenyl-1-picrylhydrazyl radical-scavenging active components from Polygonum multiflorum thunb. J. Agric. Food Chem. 1999 Jun;47:2226-2228.

27. Naik GH, Priyadarsini KI, Satav JG, Banavalikar MM, Sohoni DP, Biyani MK, Mohan H. Comparative antioxidant activity of individual herbal components used in Ayurvedic medicine. Phytochemistry. 2003 May;63:97-104.

28. Lôbo de Araújo A, Radvanyi F. Determination of phospholipase A2 activity by a colorimetric assay using a $\mathrm{pH}$ indicator. Toxicon. 1987;25:1181-1188.

29. Hong Y, Lin S, Jiang Y, Ashraf M. Variation in contents of total phenolics and flavonoids and antioxidant activities in the leaves of 11 Eriobotrya species. Plant Foods Hum Nutr. 2008 Dec;63:200-204.

30. Burda S, Oleszek W. Antioxidant and antiradical activities of flavonoids. J. Agric. Food Chem. 2001 Jun;49:2774-2779.

31. Majo DD, Giammanco M, Guardia ML, Tripoli E, Giammanco S, Finotti E. Flavanones in Citrus fruit: Structure-antioxidant activity relationships. Food Research International. 2005 Dec;38:1161-1166.

32. Dai J, Mumper RJ. Plant phenolics: extraction, analysis and their antioxidant and anticancer properties. Molecules. 2010;15:7313-7352.

33. Manthey JA, Grohmann K, Guthrie N. Biological properties of citrus flavonoids pertaining to cancer and inflammation. Curr. Med. Chem. 2001 Feb;8:135-153. 34. Ravipati AS, Zhang L, Koyyalamudi SR, Jeong SC, Reddy N, Bartlett J, Smith PT, Shanmugam K, Munch G, Wu MJ, Satyanarayanan M, Vysetti B. Antioxidant and anti-inflammatory activities of selected Chinese medicinal plants and their relation with antioxidant content. BMC Complement Altern Med. 2012 Oct;12:173. 35. Hertog MG, Feskens EJ, Hollman PC, Katan MB, Kromhout D. Dietary antioxidant flavonoids and risk of coronary heart disease: the Zutphen Elderly Study. Lancet. 1993 Oct;342:1007-1011.

36. Lee M-K, Moon S-S, Lee S-E, Bok S-H, Jeong T-S, Park YB, Choi M-S. Naringenin 7-O-cetyl ether as inhibitor of HMG-CoA reductase and modulator of plasma and hepatic lipids in high cholesterol-fed rats. Bioorg. Med. Chem. 2003 Feb;11:393-398.

37. Elangovan V, Sekar N, Govindasamy S. Chemopreventive potential of dietary bioflavonoids against 20-methylcholanthrene-induced tumorigenesis. Cancer Lett. 1994 Nov;87:107-113.

38. Ogasawara M, Matsunaga T, Suzuki H. Differential effects of antioxidants on the in vitro invasion, growth and lung metastasis of murine colon cancer cells. Biol. Pharm. Bull. 2007 Jan;30:200-204.

39. Rauha JP, Remes S, Heinonen M, Hopia A, Kähkönen M, Kujala T, Pihlaja K, Vuorela H, Vuorela P. Antimicrobial effects of Finnish plant extracts containing flavonoids and other phenolic compounds. Int. J. Food Microbiol. 2000 May;56:3-12.

40. Cushnie TPT, Lamb AJ. Antimicrobial activity of flavonoids. International Journal of Antimicrobial Agents. 2005 Nov;26:343-356.

41. Song F-L, Gan R-Y, Zhang Y, Xiao Q, Kuang L, Li H-B. Total phenolic contents and antioxidant capacities of selected chinese medicinal plants. Int J Mol Sci. 2010;11:2362-2372.

42. Lee C-H, Wu S-L, Chen J-C, Li C-C, Lo H-Y, Cheng W-Y, Lin J-G, Chang Y-H, Hsiang C-Y, Ho T-Y. Eriobotrya japonica leaf and its triterpenes inhibited lipopolysaccharide-induced cytokines and inducible enzyme production via the nuclear factor-kappaB signaling pathway in lung epithelial cells. Am. J. Chin. Med. 2008;36:1185-1198.

43. Li RW, David Lin G, Myers SP, Leach DN. Anti-inflammatory activity of Chinese medicinal vine plants. $J$ Ethnopharmacol. 2003 Mar;85:61-67. 